\title{
An Agent-Based Reasoning of Impacts of Regional Climate Changes on Land Use Changes in the Three-River Headwaters Region of China
}

\author{
Tao Zhang, ${ }^{1}$ Jinyan Zhan, ${ }^{1}$ Juan Huang, ${ }^{1}$ Rui Yu, ${ }^{2}$ and Chenchen Shi ${ }^{1}$ \\ ${ }^{1}$ State Key Laboratory of Water Environment Simulation, School of Environment, Beijing Normal University, Beijing 100875, China \\ ${ }^{2}$ Faculty of Resources and Environmental Science, Hubei University, Hubei, Wuhan 430062, China \\ Correspondence should be addressed to Jinyan Zhan; zhanjy@bnu.edu.cn
}

Received 23 May 2013; Revised 27 July 2013; Accepted 6 August 2013

Academic Editor: Xiangzheng Deng

Copyright (C) 2013 Tao Zhang et al. This is an open access article distributed under the Creative Commons Attribution License, which permits unrestricted use, distribution, and reproduction in any medium, provided the original work is properly cited.

\begin{abstract}
The land surface in Three-River Headwaters Region (TRHR), a typical ecological fragile zone of China, is quite sensitive to the climate changes which will destabilize certain ecosystem services valuable to the entire nation and neighboring countries. This study aimed to analyze the impacts of climate changes and agents' adaptive behaviors on the regional land use changes with the agent based model (ABM). First, the main agents were extracted according to the production resources endowments and socioeconomic background. Then the agents' land use behaviors were analyzed and parameterized. Thereafter, the ABM model was built to simulate the impacts of the climate changes on the regional land use changes and agents' economic benefits. The results showed that the land use changes were mainly characterized by the increase of grassland and decrease of unused land area. Besides, the agents would get more wealth under the scenario without climate changes in the long term, even though the total income is lower than that under the scenario with climate changes. In addition, the sensitivity analysis indicated that the model is sensitive to the climatic conditions, market price of agricultural and animal husbandry products, government subsidies, and cost control.
\end{abstract}

\section{Introduction}

Both the global and regional climate changes have greatly undermined the terrestrial landscapes, ecological processes, and ecosystem services [1-4], which have subsequently threatened not only the human societies but also the natural environment itself by the recondite feedback effects [5-8]. There have been dramatic changes in the climatic conditions of China, which will continue to last for a long time in the future. The atmospheric temperature of China has increased by $0.5-0.8^{\circ} \mathrm{C}$ in the 20 th century, with the upper limit exceeding the global average level. Meanwhile, the precipitation has continuously decreased in northern part of China while increased greatly in the southern and southeast part of China. Additionally, the extreme climate and subsequent natural disasters have also showed a longitudinal distribution pattern. A number of researchers have reported the impacts of climate changes on various factors of the ecological and social systems $[9,10]$, such as terrestrial surface $[10-12]$, the market price $[13,14]$, and externality of public goods and even the political negotiations among various stakeholders $[15,16]$.

Climate changes associated with human adaptive activities, especially the social agents' decisions on land use, have exerted synergistic impacts on the land surface at different scales $[11,17,18]$. There are generally two approaches through which the climate changes influence the dynamic land surface properties, that is, the natural processes and human adaptive behaviors. The natural processes, for example, the change of thermodynamic properties and hydrological changes, will alter the terrestrial land surface at the long-term scale, and the inherent properties of different land cover types limit the land use activities of human beings, while the human adaptive behaviors may mitigate the adverse effects of climate changes through changing the land use practices. For instance, the herdsmen prefer pasturing sheep on the grassland to other land cover types, and therefore they may transform the cultivated land and forest land into grassland so as to adapt to the climate changes and obtain more 


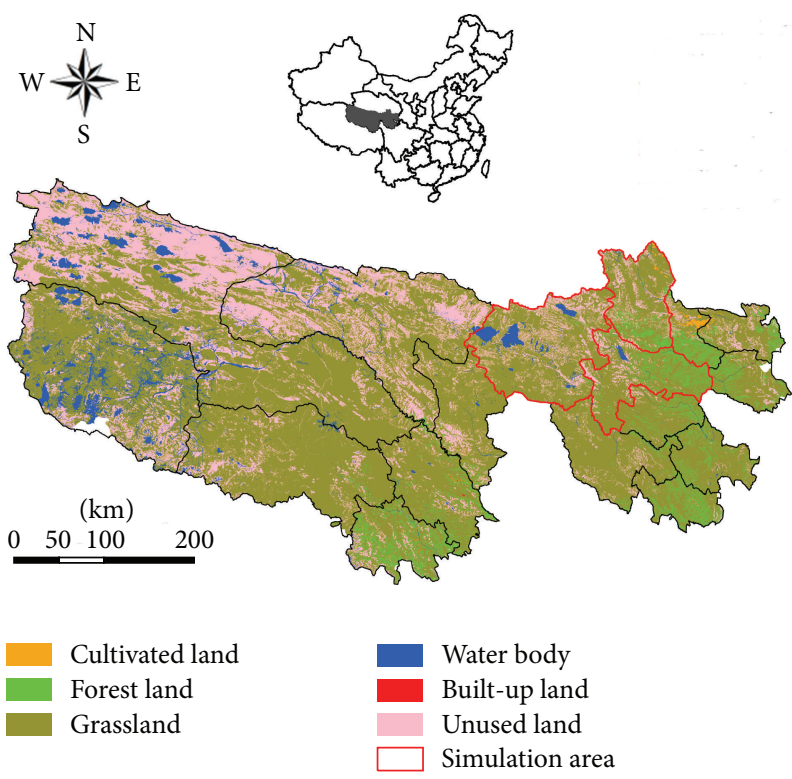

Figure 1: The location of study area. The simulation area, a continuous region involving all the land use types, was selected to implement the simulation with the ABM model. This figure shows the land use map in 2005.

ecosystem services. However, there has been very limited knowledge on the impacts of climate changes on the land use dynamics through disturbing microagents' behaviors so far. Besides, the climate change has also influenced the behaviors of government agents, who have taken measures to mitigate the impacts of the climate change and may subsequently influence the behaviors of other agents. For example, the long-term strategic development policy in the western region of China has greatly promoted the ecological restoration and protection of the regional ecosystem; the subsequent national wide policies of Grain for Green (GFG) and Overgrazing Forbidden have made remarkable progresses in the land planning and ecological construction through compensating farmers and herdsmen for the change of their unreasonable land use practices; what is more important is that the establishment of the Three-River Headwaters Region Nature Reserve has imposed restrictions on the local human land use practices and consequently protected the local ecological environment.

It is necessary to analyze the driving mechanism of social agents' behaviors and clarify their behaviors or decision algorithms with a proper model in order to more accurately study the temporal and spatial transitions of land use under the impacts of the climate change and social agents' behaviors. The agent-based model (ABM) is a mainstream model to specify the behaviors of agents. Although there have been many $A B M$ studies on the regional and local simulation, especially in the urban areas and transition zones between cultivated land and grassland, it is still necessary to carry out more in-depth ABM studies in areas without significant land use and land cover change (LUCC) and easy-distinguished agents. Besides, previous researches on the identification and parameterization of the agents' behaviors have mainly relied on the mathematical or econometric theories, which are different from the thinking ways of human beings from the ethological perspective in the real life. What is more, agents will actually choose the land use practices for a targeted land parcel according to their own or neighbors' successful land use experiences, which has served as the theoretical basis of the case based reasoning (CBR) in this study.

The Three-River Headwaters Region (TRHR), covering a total area of $37.2 \times 10^{5} \mathrm{~km}^{2}$, is located in the south of Qinghai Province, China, and it accounts for $51.9 \%$ of total provincial area. The annual average temperature and precipitation in this area are $3.96^{\circ} \mathrm{C}$ and $500 \mathrm{~mm}$. respectively, with an annual increment of $0.04^{\circ} \mathrm{C}$ and $0.17 \mathrm{~mm}$. The grassland is the dominant land use type in this area, accounting for $71.5 \%$ of the study area and having a total decrement of $0.03 \%$ in the past two decades, while the unused land accounted for $16.5 \%$ of the study area and increased by $0.10 \%$ in the same period (Figure 1). The high and mediate coverage grasslands have experienced continuous shrinkage, while the low coverage grassland area has had continually expanded. The spatial pattern of land use changes in the past decades was characterized by the grassland degradation in the middle and east regions and the shrinkage of the water body in the north and west regions [19]. Besides, the economy in the study area has experienced unprecedented development during the past 20 years. The gross domestic product (GDP) in 2010 is 15 times of that in 1990. The animal husbandry is the dominant sector in the primary industry of this region, appropriately accounting for $79.5 \%$ of the total output of the primary industry.

This study has aimed to analyze the impacts of climate changes and variability and corresponding agents' adaptive land use decisions on the land surface in the TRHR with the agent-based model. This paper will firstly extract the main agents based on the analysis of production resources endowments and socioeconomic situation in the study area and then parameterizes the behaviors of various agents by utilizing county level statistical data and household survey data. Thereafter the ABM model was constructed and used to simulate the land use changes in the next 50 years. The economic benefits of agents are also discussed in this paper.

\section{Data and Methodology}

2.1. Data Collection. The data used in this study mainly includes the land use data, socioeconomic and demographic information, the natural environment and climatic conditions, all of which were derived from the following sources: (1) Environmental Science Data Center of Chinese Academy of Sciences, which offers the datasets of land use, digital elevation model (DEM), topography, the distance to water and road, and climate and soil properties; (2) statistical yearbooks, such as Qinghai Province Statistical Yearbook, China Agricultural Yearbook, and China Animal Husbandry Yearbook, which mainly contain the population, GDP, food production, and animal husbandry production; (3) household survey data, which were obtained from the household 
survey implemented by the research team in August and October 2012 with the stratified random sampling method performance. Three counties were selected as the sample sites to conduct the survey, which aims to identify the agents and parameterize their behaviors. The questionnaires have been modified after the pretest. Besides, an intraday examination was carried out on the result of questionnaires so as to revise the inconsistent or unreasonable answers with the retelephone investigation. This could not only save a lot of human resources and finance but also ensure the representativeness and reliability of the samples.

2.2. Identification of Agents. It is more difficult to identify the agents in the study area than in other regions where the agents such as farmers and herdsmen have inherent differences. In the study area, most people are herdsmen who rely on the grassland, and it seems that there are no absolute differences among these individuals. However, the statistical analysis and preinvestigation indicate that the herdsmen are different in the economic background and production resources, which would influence their land use decisions. Therefore, based on the analysis of the socioeconomic background, natural environment conditions, and resources endowments, all the counties in the study area were classified into three categories, that is, the traditional development area, animal husbandry dominated area, and restricted development area. By doing this, the major agents can be extracted from each category, including the farmer agent, herdsman agent, and hominid agent.

The farmer agents are mainly located in the traditional development areas, eastern regions. They possess abundant labor force, production resources, and relatively large cultivated land area, which help them get a higher economic return from diverse income sources. The herdsman agents mainly dwell in the animal husbandry dominated areas, where the cultivated land shares a very small proportion, but the grassland occupies more than $70 \%$ of the total area of these regions. So the herdsmen extremely rely on the grassland to develop the animal husbandry industry to get the revenue for supporting their families. Subsequently, the proportion of animal husbandry output to the primary industry output is higher than other sectors due to the intensive resources utilization and collective land use practices. The hominid agents were identified according to the habitat properties. The hominid agents were located in the counties where the social and natural ecological systems are extreme fragile. These counties are characterized by the harsh climatic conditions, lower economic levels and human resource, and lack of production resource endowments. Therefore, the agents in these areas would heavily rely on the natural conditions rather than the land use activities to support their life.

2.3. Agents' Behaviors. The general behavior rules of how the agents decide the land use practices for a targeted land parcel were introduced first, and then the individual behavior rules that varied from each agent were designed and specified with the diverse characteristics. At last, the impacts of the government agent's behaviors on other agents' decision through punishment and compensation were described.

Generally, all the agents have the same procedures of determining the land use practices for a certain land parcel. It means that each agent will choose a land use type for a land parcel at the beginning of each simulation step; then the agent will calculate the maximum combined economic and social benefit at the end of each step to decide which land use type should be chosen for this land parcel. Thereafter the agent chooses a certain land use type according to the land use decision algorithm. Finally, the agent will decide whether or not to sell or buy land parcels based on the estimation of economic account [20].

The individual behavior rules are different among agents due to the variation of economic background, natural conditions, and production resource endowments, which are vital to the design of the land use decision algorithm. There are three categories of individual decision algorithms in terms of satisfaction, imitation, and case-based reasoning (CBR) strategies [21]. It was assumed that agents have different probabilities to choose the decision algorithm according to the results of the field survey. Specifically speaking, if the benefits of the land use decision have reached the agents' expectation, the agents will choose the satisfactory land use strategy, that is, choose the same land use type in last year. Or else the agents will get certain probabilities to choose the imitation strategy or CBR strategy if the expectation is not realized [21]. As for the imitation strategy, the agents will imitate the successful land use practices of their neighbors. But actually all the agents are more willing to determine the land use for the land parcel according to their own historical experiences. Therefore, they will get a relative higher probability to choose the CBR strategy.

The CBR strategy is an approach to acquire the solutions to land use decisions through analyzing the historical experience. It can simplify the knowledge, improve efficiency, and update the cases [20]. Each case records one agent's land use experiences in a specific land parcel, which includes the year, biophysical characteristics of the land parcel, climatic conditions, land use type, and economic and social benefits. Cases in the model can be sorted and updated through putting the latest case in the forefront of the retrieval store when running the model [21]. The agents will retrieve the case store to find the most appropriate case that matches the properties and conditions in the simulation year. By doing this, the agents can effectively and quickly collect detailed information such as the economic and social benefits and land use type to decide whether or not to choose this land use type. Actually, as for the utilization of CBR to describe the agents' behaviors, the memory capacity of the agents is limited by the memory time and size. It is assumed that the agents can always remember several latest cases but not forever. And what is more important is that the excessive cases will decelerate the retrieval speed and require advanced hardware configurations.

The government agent relies on the participation message interface to pass parameters in the model, so it is also necessary to conduct quantitative and positioning analyses. In the ABM model, it is assumed that the government 
agent pays more attention to the ecological and environmental problems, and the government agent's behaviors were parameterized on the basis of the ecological compensation policies and land planning. With regard to the ecological compensation policies, a specific analysis was conducted with the Grain for Green policy as an example. The Grain for Green policy insists that the government should offer some compensation for the conversion from cultivated land to forestry area or grassland, and there is no restriction on the total amount of compensation fee to practitioners, given that the amount of compensation fee is just related to the total land conversion area. Besides, the nature reserves and future land planning will be considered, all of which are the bases to support the parameterization of the government agent's behaviors.

2.4. Key Factors of Agents' Behaviors. Table 1 shows the key influencing factors of the agents' behaviors, such as socioeconomic background, bad events, and human awareness to society and natural conditions. Since these factors can trigger the agents' behaviors and destabilize the magnitude of activities, different parameters of these factors were used to specify the land use decisions of agents.

The total economic account of agents, which comprises of initial account, agricultural income, nonagricultural income, and government compensation, can influence the agents' behaviors through the bid amount of land transformation and market prices of agricultural and animal husbandry products. The agents who own more wealth (higher purchasing power) are more willing to buy land parcels in the land transformation step (higher bid amount). The statistical data indicated that there is a difference in the initial accounts of agents, and the nonagricultural income of the farmer agents is higher than other agents. Besides, the agricultural income depends on the production and market prices; therefore it is assumed that the agents are willing to change the cultivated land into grassland if the prices of animal husbandry products are higher than that of the agricultural products. In addition, there is also difference in the land use properties of different agents, which will further lead to the difference in their behaviors. Generally, the land use of last simulation step determines the result of the next simulation step. For example, if one agent chooses the satisfactory strategy according to the land use algorithm, the land use of last year will be selected for the targeted land parcels. Moreover, small land parcels are relatively easier to be converted, and therefore their land conversion probabilities would be higher than plots within larger areas, and the agents' wealth and the area of each land use type are not the same; different land use types with different areas require diverse investments and cost. Therefore, the configuration of relevant parameters are different among these agents and land use types. What is more, there are still some other factors that may influence the agents' decisions through destabilizing their balance analysis between two-dimensional benefits of economic returns and social acceptance, such as the initial human awareness and natural disasters. For example, agents who have large population and high economic revenue and lack the needed ecosystem services may pay more attention to the social benefits and ecosystem services rather than the economic return. The agents who suffered from natural disasters may also reanalyze the two-dimensional benefits.

2.5. Parameterization and Validation. The parameters of the ABM model mainly include the model parameters and agents' parameters. The model parameters include the topology, neighbor radius, and cell numbers and sizes, all of which are the same for all the kinds of agents. These model parameters were mainly set on the basis of the statistical data at the county level, while the agents' parameters were primarily set according to the results of county classification and household survey data. In addition, the time delay of land use was taken into account in this study. There is some time delay in the impacts of the social agents' adaptions and government policies on the land use change. The agents cannot immediately change the land use practices of targeted parcels even if the income loss appears; it will take them some time to make sure whether they will change the land use practices or not. Therefore the parameter of the model was adjusted on the basis of the time delay.

The land use structure and pattern in 1995 and 2005 were first simulated on the basis of land use data of 1988 and then compared with the actual land use data so as to validate and calibrate the simulation model. The validation methods include the point to point comparison, Kappa index, Moran I index, and ROC curve. The results of all the tests showed that the ABM model has a good simulation capacity, but the result of the ROC test indicates there are also some potential uncertainties. The ROC curve showed that the simulation results of cultivated land and built-up land were not as good as those of other land use types, which may be due to the rough simulation resolution. The ABM model was finally calibrated through changing the sensitive parameters on the basis of the trials and errors.

\section{Results and Discussion}

This study aims to explore the impacts of climate changes on the land use changes and the agents' economic benefits in the Three-River Headwaters Region. The land use changes were simulated under two scenarios, one with the climate changes and the other without the climate changes.

3.1. Land Use Changes. Most land use types except the cultivated land will change in a similar trend under both of the two scenarios. The simulation result suggests that the grassland and the built-up land will show an increasing trend, while the forest land and unused land will tend to shrink in the simulation period. On the whole, the area of grassland and unused land will change most greatly. More specifically, there is obvious change in the grassland area, with an increment rate of approximately 5.1\% under the scenario with climate changes and $6.0 \%$ under the scenario without climate changes. On the contrary, the areas of forest land and unused land will decrease during the same period. The area of forest land will decrease by $23.4 \%$ and $33.7 \%$ 
TABLE 1: The factors that impact the agents' behaviors.

\begin{tabular}{|c|c|c|}
\hline Categories & Variables & Impacts on behaviors \\
\hline \multirow{2}{*}{ Climate } & Temperature & \multirow{2}{*}{$\begin{array}{l}\text { Different climatic conditions determine the agents' land use practices; for example, mild } \\
\text { climate is suitable for cropping, pasturing, and so forth. }\end{array}$} \\
\hline & Precipitation & \\
\hline \multirow{3}{*}{ Economy } & Initial account & \multirow{3}{*}{$\begin{array}{l}\text { The amount of the agents' account impacts their land use practice, such as investment, land } \\
\text { bid, and cost control. }\end{array}$} \\
\hline & Nonagricultural income & \\
\hline & Price & \\
\hline Bad events & Natural disasters & Weight of balancing the economy and nature. \\
\hline \multirow[t]{2}{*}{ Policy } & GFG & $\begin{array}{l}\text { The compensation can stimulate the agents to transform other land uses into grassland and } \\
\text { forest land. }\end{array}$ \\
\hline & Nature reserve & Ban the agents' land use practices in the core area. \\
\hline \multirow{2}{*}{ Topography } & Distance to water & \multirow{2}{*}{$\begin{array}{l}\text { The conversion area of grassland to cultivated land decreases with the increment of distance } \\
\text { to water and slope. }\end{array}$} \\
\hline & Slope & \\
\hline \multirow{3}{*}{ Soil property } & Soil nitrogen & \multirow{3}{*}{ Agents are willing to keep the fertile land parcel as grassland. } \\
\hline & Soil phosphorous & \\
\hline & Soil potassium & \\
\hline \multirow[t]{2}{*}{ Land use } & \multirow[t]{2}{*}{ Land use } & $\begin{array}{l}\text { The initial land use determines the results of next step. } \\
\text { The land use type and area determine the probabilities of land use change. }\end{array}$ \\
\hline & & The land use type and area determine the probabilities of land use change. \\
\hline
\end{tabular}

and under the scenario with and without climate changes, respectively, while that of the unused land will be $14.6 \%$ and $8.7 \%$, respectively (Figure 2 ). Therefore, the climate changes will lead to the decrease of cultivated land and unused land and the increase of forest land and grassland by comparing the results of these two scenarios on the whole.

The area of the cultivated land, water body and builtup area will fluctuate strongly under the two scenarios. The cultivated land area will decrease to some degree under the scenario with climate changes and show an opposite trend under the other scenario. However, there are similar changing trends of the area of the water body and built-up land under these two scenarios but with more wide fluctuation range under the scenario with climate changes. This may be due to the rough simulation resolution. The land parcel was set as the basic unit for land use decision, which means that the agent will change the land use practices of all the land cells in the targeted land parcel. However, there were initially only 5 built-up land cells in the $2 \mathrm{~km}$ resolution data, and the smallest land parcel in the study area consists of 9 grid cells; as a result the resolution of the data leads to some errors in the simulation result. Besides, another reason may be the probability of climate change and the parameterization of the agents' behaviors, which account for the fluctuation of land use types in the large area. The probability of climate changes will influence the output of land use, which will further influence the agents' income, and therefore the agents will change their land use practices to adapt to the climate changes. In addition, there may be amplified impacts of climate changes on the land use changes on condition that the parameters of the agents' behaviors were not set reasonably.

3.2. Regional Economy. The change of the economic return was also simulated with the ABM model under different climate change scenarios. The economic return of agents mainly comes from three sources, that is, the agricultural income from the land parcel harvest, nonagricultural income, and government subsidies. The simulation results show that the climate changes will lead to a stable growth of the agents' wealth in the long term, and the agents' income will be higher under the scenario without climate changes, showing an exponentially increasing trend.

The herdsman's annual income is more than that of the other two agents since they own more grassland, from which the major income of the animal husbandry comes (Figure 3). Besides, the annual income of all agents showed a more optimistic changing trend under the scenario without climate changes. The change of the annual income of the farmer agents is similar to that of the hominid agent, showing an exponentially increasing trend. The annual income of the farmer agent will show a growing trend during the initial 25 years, followed by a declining trend under the scenario with climate changes. By contrast, the annual income of the hominid agent will be relatively more stable. In general, the total income of agents under the scenario without climate changes is lower than that under the scenario with climate changes (Figure 4). However, the total income of the farmer agent and hominid agents will show an exponentially increasing trend under the scenario without climate changes and a steadily growing trend under the scenario with climate changes. In summary, the agents will get more wealth under the scenario without climate changes in the long run.

3.3. Sensitivity Analysis. In order to analyze sensitivity of the cell numbers of cultivated land and grassland, total income of agents, and yield of land parcels to the driving factors listed in Table 1, the relative sensitivity was analyzed with the following formula:

$$
S=\frac{(Y(X+\Delta X)-Y(X)) / Y(X)}{\Delta X / X},
$$



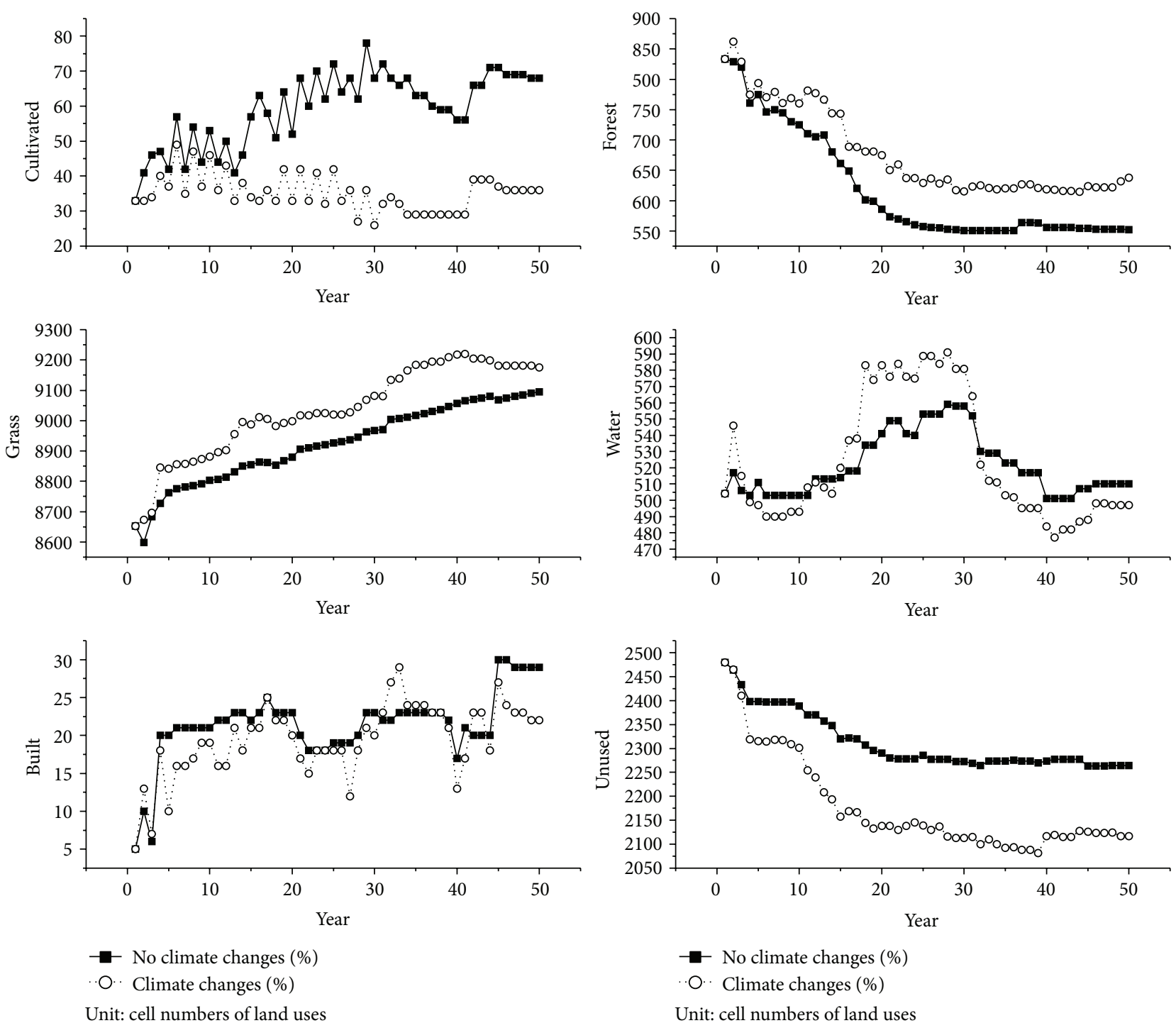

FIGURE 2: Simulation results of the land uses under the scenario with and without climate changes. The picture shows the cell numbers of each land use in every simulation step.

TABLE 2: Results of the sensitivity analysis, unit: \%.

\begin{tabular}{lcccc}
\hline Variables & $\begin{array}{c}\text { Cell numbers } \\
\text { of cultivated } \\
\text { land }\end{array}$ & $\begin{array}{c}\text { Cell numbers } \\
\text { of grassland }\end{array}$ & $\begin{array}{c}\text { Total } \\
\text { income }\end{array}$ & Yield \\
\hline Temperature & 1.05 & -0.26 & -0.16 & 1.31 \\
$\begin{array}{l}\text { Precipitation } \\
\begin{array}{l}\text { Price of products } \\
\text { of agriculture }\end{array}\end{array}$ & -0.66 & 1.30 & 1.93 & 2.09 \\
$\begin{array}{l}\text { Price of products of } \\
\text { animal Husbandry }\end{array}$ & -0.77 & 0.16 & 0.21 & 0.95 \\
$\begin{array}{l}\text { Government } \\
\text { subsidies }\end{array}$ & -1.75 & 2.62 & 8.31 & 1.95 \\
Cost control & -1.97 & 2.02 & 2.07 & 0.25 \\
\hline
\end{tabular}

where $Y(X+\Delta X)$ is the simulated result after the change of inputs, $Y(X)$ is the background result, and $\Delta X$ is the change of input variables. The relative sensitivity represents the change of the result after the change of only one variable. The greater the change of the results is, the more sensitive to the input variables the results are. This study mainly focused on the sensitivity to the climate changes, market price, government policies, and cost control.

The result of sensitivity analysis indicated that the grid numbers of the cultivated land and grassland have a higher sensitivity to the prices of products of the agriculture and animal husbandry, government subsidies, and cost control (Table 2). Besides, the total income is more sensitive to the prices of products of the agriculture and animal husbandry, cost control, government subsidies, and precipitation. What is more, yield has a higher sensitivity to the cost control, precipitation, the prices of products of the agriculture and animal husbandry, and temperature. In summary, the prices of products of agriculture and animal husbandry, precipitation, subsidies from government for land use change, and cost 

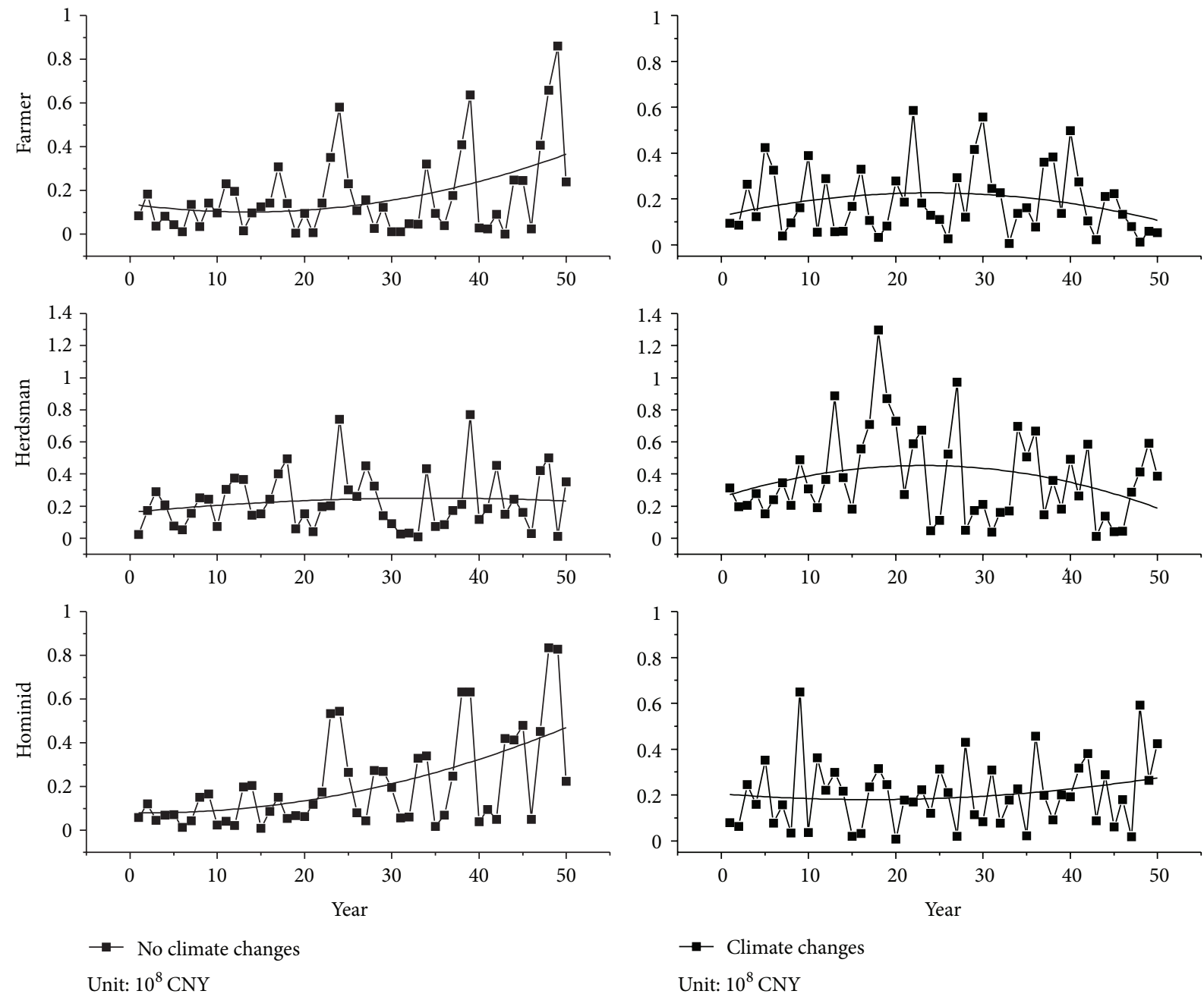

(a)

(b)

FIGURE 3: Simulation result of annual income change of agents under the scenario with (b) and without climate changes (a).

control have significant influence on the land use changes and economic return in the study area.

\section{Conclusion}

The climate changes can alter the land surface properties through influencing the human land use practices, and the ABM model is a good tool to study these climatic effects. The Three-River Headwaters Region was selected as the study area, where it is quite sensitive to the climate changes but has the characteristics of moderate land use changes and agents that are difficult to identify. The agents are identified and extracted and parameterized through analyzing the survey data and county level statistical data. Then the ABM model was established and used to simulate the dynamic land use changes under different climate change scenarios. In addition, CBR as an approach that is similar to the agents' thinking way in real life was used to parameterize the agents' behaviors in this study.
The results showed that the future trends of land use changes in the study area will be mainly characterized by the increase of grassland and decrease of unused land. A set of factors in terms of climate changes, agents' decisions, and government policies will affect the dynamic process of regional land surface. Besides, the result indicated that the model is quite sensitive to the climate changes, prices of agricultural and animal husbandry products, government subsidies, and cost control. Therefore, more importance should be attached to market price adjustment, stimulating policies implementation, and emerging technologies promotion, to lead reasonable land use practices so as to promote the reasonable land use practices, maintain the integrality and sustainability of ecosystems, and guarantee the provision of ecosystem services in the long term.

In this study, only the climate changes and agents' decisions on land use were taken into account. However, the household survey indicates that the agents' behaviors may be greatly affected by the governmental subsidies and the market 

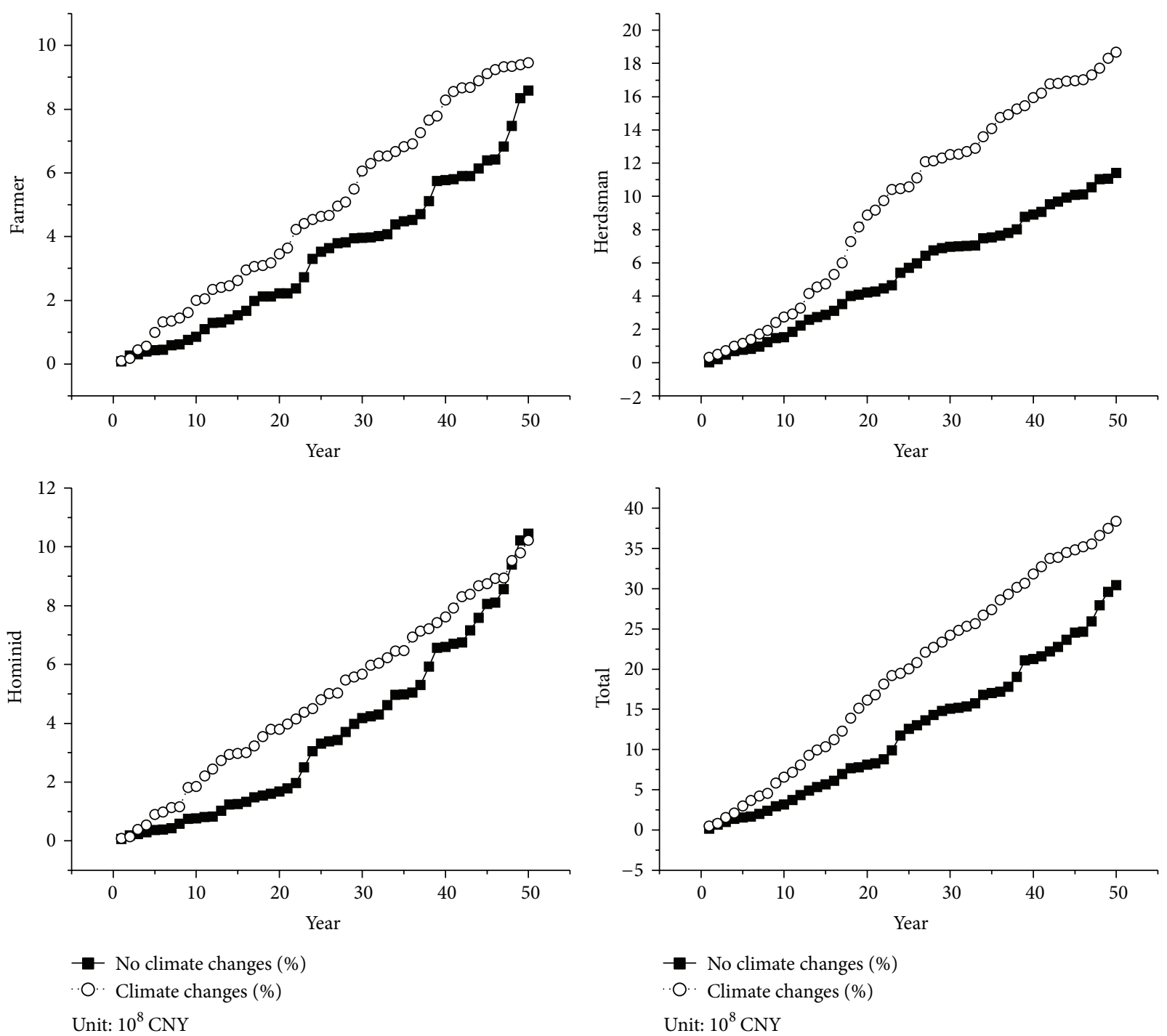

FIGURE 4: Simulation result of the change of total income of agents under different climate change scenarios.

prices that influence their economic income, which can be also illustrated with the sensitivity analysis. Therefore, more importance should be attached to the socioeconomic state when analyzing its impacts on the land use and terrestrial surface change in the future researches.

\section{Acknowledgments}

This research was supported by the National Basic Research Program of China (973 Program) (no. 2012CB95570001), the National Key Programme for Developing Basic Science in China (no. 2010CB950904), and the Key Project in the National Science \& Technology Pillar Program of China (no. 2013BAC03B00). Exploratory Forefront Project for the Strategic Science Plan in IGSNRR, CAS, is also greatly appreciated.

\section{References}

[1] H. O. Pörtner and A. P. Farrell, "Physiology and climate change," Science, vol. 322, no. 5902, pp. 690-692, 2008.

[2] D. Schröter, W. Cramer, R. Leemans et al., "Ecosystem service supply and vulnerability to global change in Europe," Science, vol. 310, no. 5752, pp. 1333-1337, 2005.

[3] R. B. Alley, J. Marotzke, W. D. Nordhaus et al., "Abrupt climate change," Science, vol. 299, no. 5615, pp. 2005-2010, 2003.

[4] A. Jentsch and C. Beierkuhnlein, "Research frontiers in climate change: effects of extreme meteorological events on ecosystems," Comptes Rendus-Geoscience, vol. 340, no. 9-10, pp. 621628, 2008.

[5] S. Kröpelin, D. Verschuren, A. M.. Lézine et al., "Climatedriven ecosystem succession in the Sahara: the past 6000 years," Science, vol. 320, no. 5877, pp. 765-768, 2008.

[6] K. F. Drinkwater, G. Beaugrand, M. Kaeriyama et al., "On the processes linking climate to ecosystem changes," Journal of Marine Systems, vol. 79, no. 3-4, pp. 374-388, 2010. 
[7] J. Jin, S. Lu, S. Li, and N. L. Miller, "Impact of land use change on the local climate over the Tibetan Plateau," Advances in Meteorology, vol. 2010, Article ID 837480, 6 pages, 2010.

[8] M. Wang, X. Zhang, and X. Yan, "Modeling the climatic effects of urbanization in the Beijing-Tianjin-Hebei metropolitan area," Theoretical and Applied Climatology, vol. 113, no. 3-4, pp. 377-385, 2013.

[9] S. Hitz and J. Smith, "Estimating global impacts from climate change," Global Environmental Change, vol. 14, no. 3, pp. 201218, 2004.

[10] T. Yue, Z. Fan, C. Chen, X. Sun, and B. Li, "Surface modelling of global terrestrial ecosystems under three climate change scenarios," Ecological Modelling, vol. 222, no. 14, pp. 2342-2361, 2011.

[11] M. Ostwald and D. Chen, "Land-use change: impacts of climate variations and policies among small-scale farmers in the Loess Plateau, China," Land Use Policy, vol. 23, no. 4, pp. 361-371, 2006.

[12] S. Briner, C. Elkin, R. Huber, and A. Grêt-Regamey, "Assessing the impacts of economic and climate changes on land-use in mountain regions: a spatial dynamic modeling approach," Agriculture, Ecosystems and Environment, vol. 149, pp. 50-63, 2012.

[13] T. Li, R. F. Grant, and L. B. Flanagan, "Climate impact on net ecosystem productivity of a semi-arid natural grassland: modeling and measurement," Agricultural and Forest Meteorology, vol. 126, no. 1-2, pp. 99-116, 2004.

[14] A. Fleischer and M. Sternberg, "The economic impact of global climate change on Mediterranean rangeland ecosystems: a space-for-time approach," Ecological Economics, vol. 59, no. 3, pp. 287-295, 2006.

[15] L. E. Rustad, "The response of terrestrial ecosystems to global climate change: towards an integrated approach," Science of the Total Environment, vol. 404, no. 2-3, pp. 222-235, 2008.

[16] C. E. Williamson, J. E. Saros, and D. W. Schindler, "Climate change: sentinels of change," Science, vol. 323, no. 5916, pp. 887888, 2009.

[17] M. D. A. Rounsevell and D. S. Reay, "Land use and climate change in the UK," Land Use Policy, vol. 26, supplement 1, pp. S160-S169, 2009.

[18] L. Zhen, L. Yang, G. D. Xie, and S. K. Cheng, "Land use dynamics and policy implications in the Jinghe watershed of western China: a critical assessment from local perspectives," Natural Resources Journal, vol. 46, no. 4, pp. 859-879, 2006.

[19] X. Xu, J. Liu, Q. Shao, and J. Fan, "The dynamic changes of ecosystem spatial pattern and structure in the three-river headwaters region in Qinghai Province during recent 30 years," Geographic Research, vol. 27, no. 4, pp. 829-839, 2008 (Chinese).

[20] J. G. Polhill, L. Sutherland, and N. M. Gotts, "Using qualitative evidence to enhance an agent-based modelling system for studying land use change," Journal of Artificial Societies and Social Simulation, vol. 13, no. 2, p. 10, 2010.

[21] L. R. Izquierdo, N. M. Gotts, and J. G. Polhill, "Case-based reasoning, social dilemmas, and a new equilibrium concept," Journal of Artificial Societies and Social Simulation, vol. 7, no. 3, p. 1, 2004. 

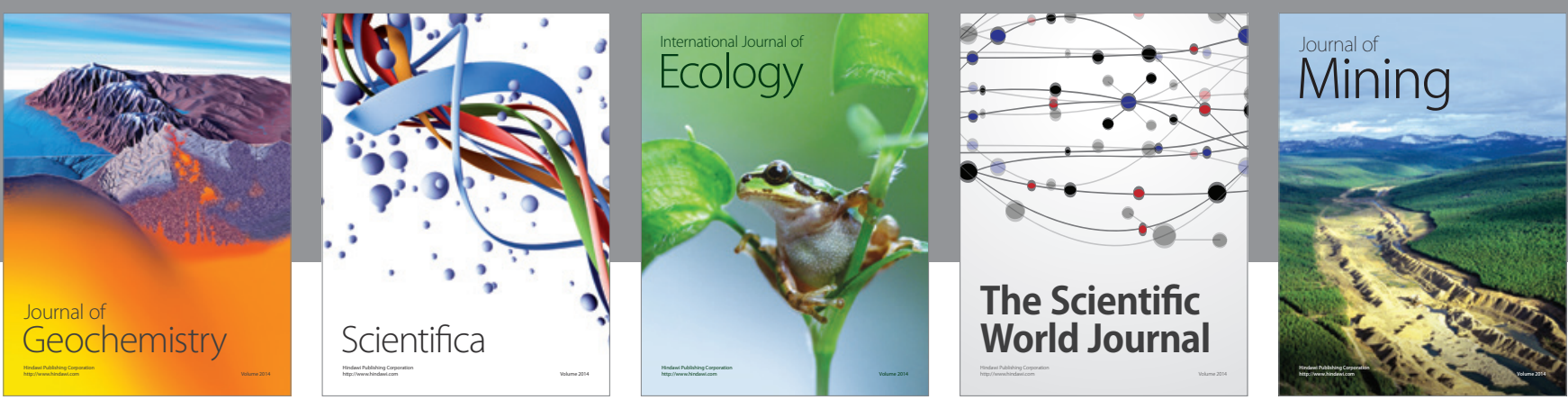

The Scientific World Journal
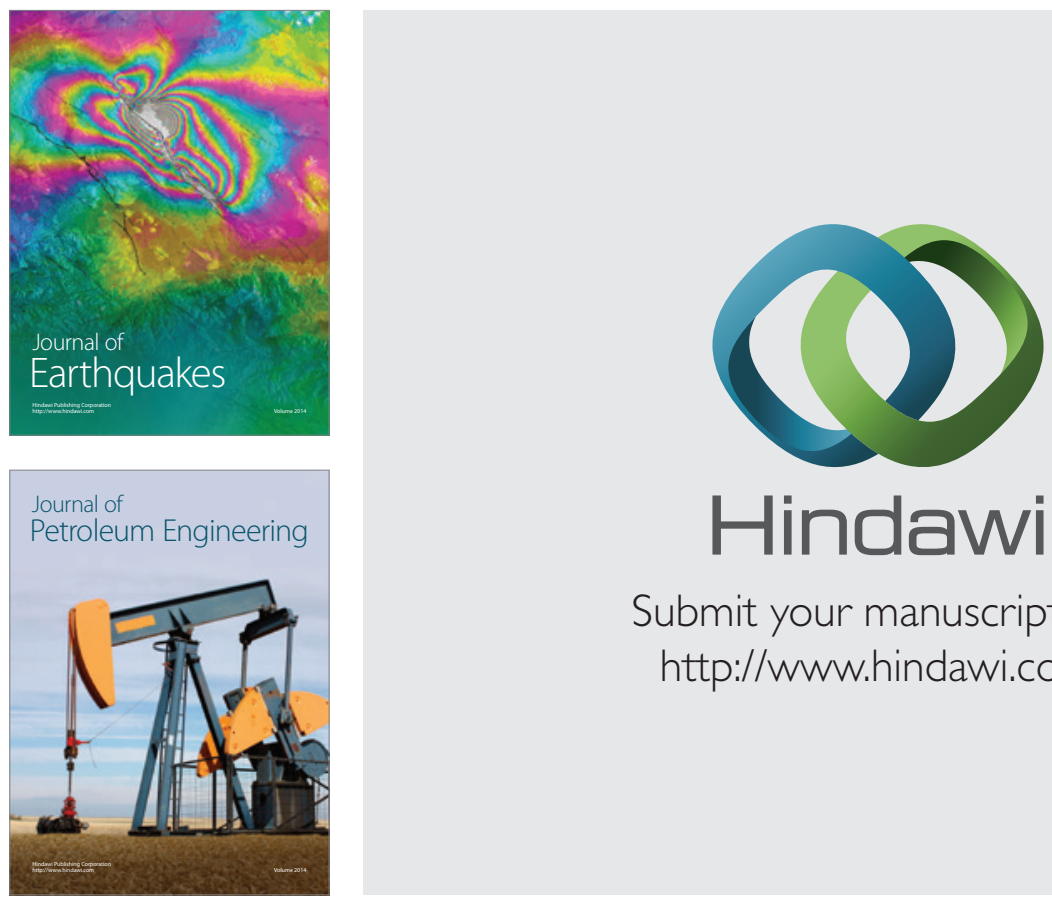

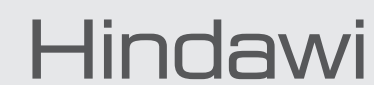

Submit your manuscripts at

http://www.hindawi.com
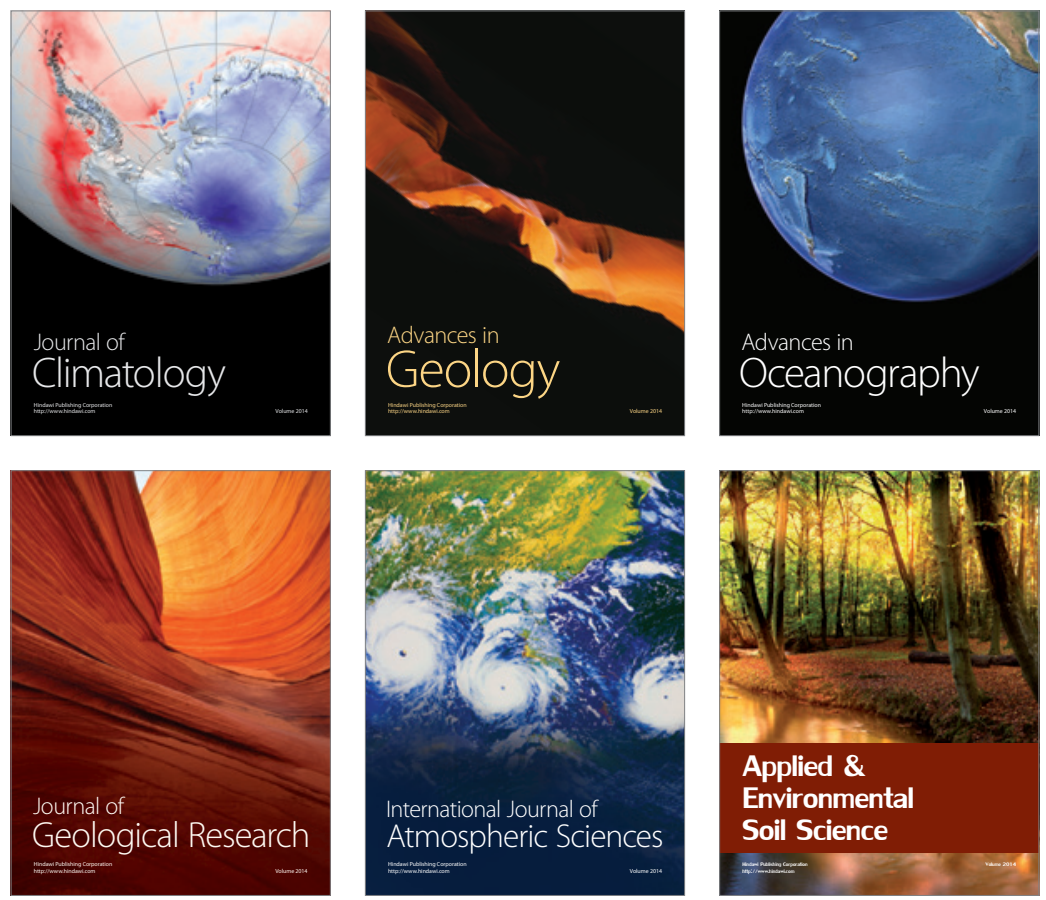
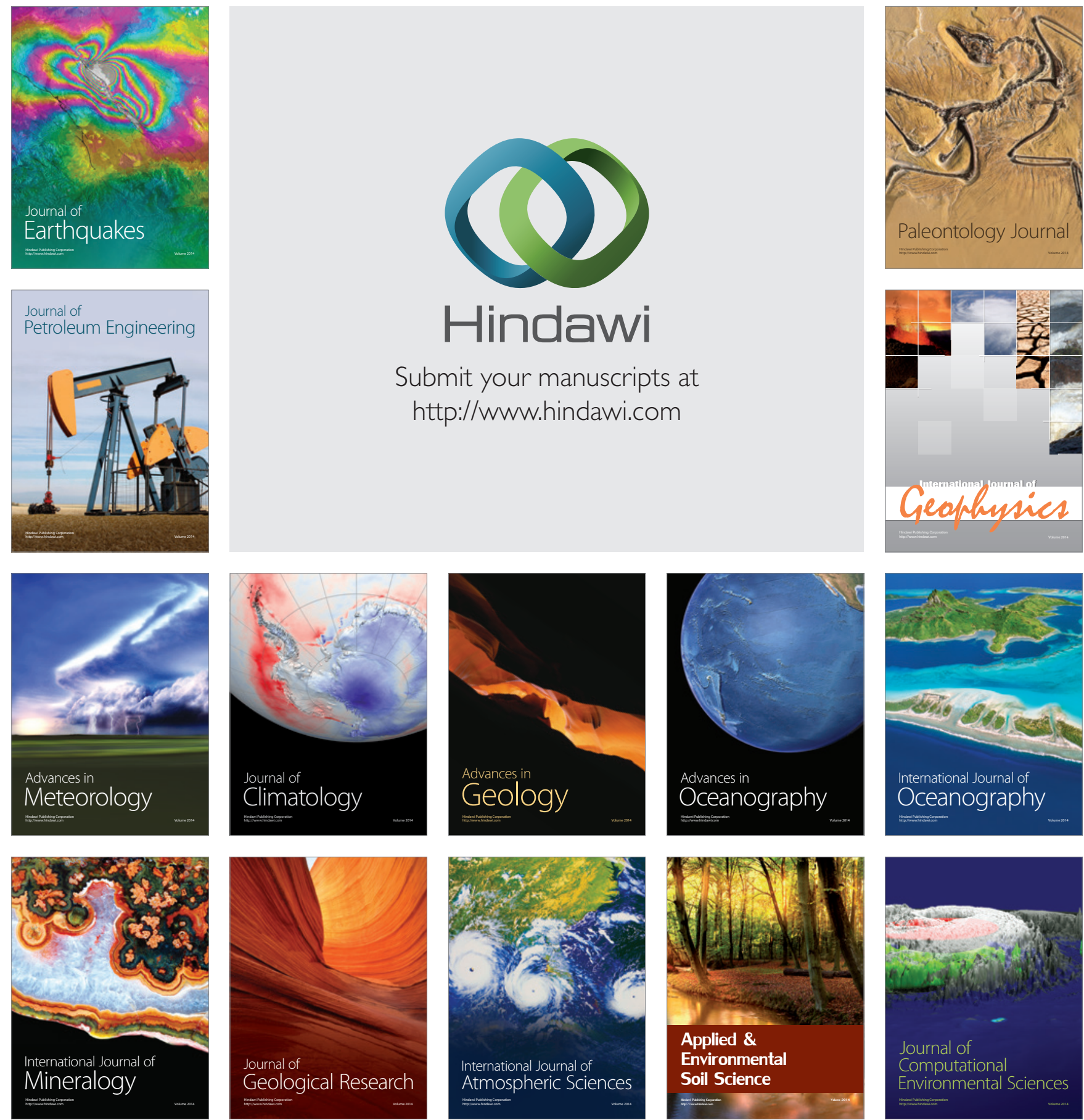